Maja Šabec

\title{
AMOR HEREOS: POJMOVANJE LJUBEZNI KOT BOLEZNI V CELESTINI FERNANDA ROJASA
}

Ključne besede: Celestina, srednjeveška književnost, bolezen ljubezen, mizoginija

\section{Tragikomedija o Kalistu in Melibeji ${ }^{1}$}

Celestina je glede na njen pomen za špansko književnost v marsičem prelomno delo. Na to napeljuje že letnica prve izdaje - 1499, ki jo umešča točno na prehod iz srednjega $\mathrm{v}$ novi vek. Ta zvrstno neopredeljiva mojstrovina ${ }^{2}$ Fernanda de Rojasa združuje v sebi nešteta nasprotja, značilna za duha časa, v katerem je nastala: po eni strani je še globoko usidrana v srednjeveškem pojmovanju človeka in področij njegovega življenja (od materialnega do duhovnega), po drugi pa že napoveduje prihajajoči renesančni humanizem in družbene spremembe, ki jih ta prinaša.

Zgodba je preprosta: postaven mlad plemenitaš Kalist nekega dne zaide na vrt someščanke, trgovčeve hčere Melibeje, in se ob pogledu nanjo nesmrtno zaljubi. A ko mladenki izpove ljubezen, se ta hudo razjezi in ga napodi. Obupanega Kalista najprej poskuša potolažiti njegov služabnik Sempronij, vendar hitro sprevidi, da ne bo kos situaciji, zato se zateče po pomoč k izkušeni zdravilki in zvodnici Celestini. Premetena starka s preizkušenimi načini posredovanja in ob pomoči Kalistovih služabnikov Sempronija in Parmena končno premaga Melibejin odpor in junaka se zaple-

1 Prvotni naslov dela je bil Komedija oz. Tragikomedija o Kalistu in Melibeji.

2 Delo je zvrstni hibrid. Nekateri ga opredeljujejo kot roman ali kot dialogizirani roman, drugi kot dramsko delo. 
teta $\mathrm{v}$ strastno ljubezensko razmerje. Toda njuna približno mesec trajajoča romanca se nesrečno konča, ko Kalisto med odhodom z nočnega skrivnega srečanja pri Melibeji spregleda klin na lestvi, omahne v prazno in se ubije. Naslednji dan umre tudi neutolažljiva Melibeja - z domačega stolpa se požene v smrt.

Ena najvidnejših značilnosti Celestine, ki ustvarjajo njen umetniški presežek, je vsenavzoča dvoumnost, ki bralca nenehno pušča v negotovosti. Čeprav se na prvi pogled zdi, da je to pri Rojasu zgolj literarna konvencija ali poigravanje, so njene implikacije veliko širše. Dvoumne namreč niso samo izjave posameznih junakov, temveč sega konfliktno prežemaje nasprotujočih si polov tako globoko, da spodmika smisel dela v celoti. Avtor na začetku sicer pove, da si je Tragikomedijo o Kalistu in Melibeji zamislil kot poučno grajo razuzdanih zaljubljencev (»compuesta en reprehensión de los locos enamorados... «) in opozorilo mladim ljudem, naj se varujejo ukan zvodnic in priliznjenih služabnikov (»en aviso de los engaños de las alcahuetas y malos y lisonjeros sirvientes «, $C, 23),{ }^{3}$ vendar se domnevna poučnost prav lahko obrne v svoje nasprotje. Celestina ponuja vsaj dve možnosti: lahko jo razumemo kot moralizirajoče delo, kakor predlaga Rojas, ali kot ironično, zabavno zgodbo, ki sprevrača vse obstoječe kánone. Hkrati je mogoče izluščiti iz besedila še nastavke za drugačne interpretacije, na primer s stališča medicine. To je tudi izhodišče za pričujoči članek, ki obravnava enega od izrazito srednjeveških vidikov Celestine - pojmovanje ljubezni kot patologije, ki naj bi ji podlegla glavna junaka in je morda glavni vzrok za tragični razplet zgodbe.

\section{Bolezen ljubezen}

Proti koncu srednjega veka so ob novem zanimanju za naravo in snovnost človeškega telesa zbudila pozornost tudi čustva, med njimi ljubezen. Ker se ta tiče hkrati telesa in duše, je bila civilizacijsko v presečišču interesnih področij zdravilstva, naravne filozofije, mistike, moralne in pastoralne teologije ter literature, vselej razpeta med kleriško in laično miselnostjo:

3 Vsi navedki iz Celestine (v nadaljevanju C) so iz izdaje Francisca Rica (2000). 
prva jo je obsojala, druga pa odobravala ali celo priporočala. Razpravljalci - med njimi tudi Rojasovi sodobniki in kolegi s salamanške univerze (npr. zdravnik Ferdinanda Katoliškega Francisco López de Villalobos) ${ }^{4}$ so sledili tradicionalnim antičnim in krščanskim utemeljitvam, po 12. stoletju so čedalje več črpali še iz arabskih virov, in jih prilagajali času. Zaradi sprememb, ki jih ljubezen povzroči v človeku, da ta svojega telesa ne more več krotiti z razumom, so mnogi gledali na to stanje kot na eno do oblik norosti (alienatio mentis), torej kot bolezen. Na tako razlago je imel velik vpliv Avicennov Kanon medicine, ki ga je v drugi polovici 12. stoletja prevedel v latinščino Gerard iz Kremone. Različne obravnave pojava ljubezni so se velikokrat prepletale, zato jih je danes težko ali nemogoče obravnavati posamično. Izrazi so izvirali tako iz retorike teološkega moraliziranja kot iz medicinskega slovarja in so jih brez razlikovanja uporabljali vsi učenjaki.

\section{Izvor in simptomi bolezni amor hereos}

Vzroke in proces obolevanja ter ustrezne metode zdravljenja ljubezni je zelo podrobno opisal ugledni zdravnik in profesor na univerzi v Montpellierju Bernard Gordonij (umrl med leti 1318 in 1320) v dvajsetem poglavju druge knjige odmevnega medicinskega priročnika Lilium medicinae. ${ }^{5}$ Španski prevod tega dela, Lilio de medicina, se je v 15. stoletju širil prek inkunabul, v salamanški univerzitetni knjižnici pa so hranili celo rokopisni primerek in Dennis Seniff (1986) se upravičeno sprašuje, ali ga je Fernando de Rojas v študijskih letih nemara prebiral, saj se njegova izbira virov v Celestini, predvsem tistih z mizoginimi podtoni, opazno navezuje na Bernardove medicinske izpeljave.

4 Njegovo delo El sumario de la medicina (1498) je prvo avtorsko didaktično-medicinsko delo $\mathrm{v}$ kastiljščini in je napisano $\mathrm{v}$ verzih.

5 Avtor je v njem poleg obveznega temeljitega poznavanja naravoslovcev in medicincev - Aristotela, Galena, Avicenne, Alberta Velikega itn. - združil še veliko širše znanje. Med zgodnjimi krščanskimi učitelji se enako pogosto sklicuje na Origena, Zlatousta, Avguština in Hieronima, med poznejšimi spisi pa predvsem na Boetijevo Filozofsko tolažbo, Bernarda Silvestrisa, Huga Svetoviktorskega, Bernarda iz Clairvauxa in enciklopedijo De proprietatibus rerum Bartolomeja Angleškega (Demaitre, 1980). 
Gordonij razlaga, da se bolezen začne s pogledom, nato pa se sproži pogubna verižna reakcija: podoba ljubljene osebe prek optičnega živca doseže čutnega duha in povzroči nered $\mathrm{v}$ »presojevalni vrlini« (virtus estimativa), tisti sposobnosti, ki nagonsko presoja, čemu slediti in čemu se izogniti. Virtus estimativa je najplemenitejši razsodnik med različnimi dojemanji čuteče duše, toda če zboli, napačno usmerja imaginacijo, da zapove poželjivosti, naj si zaželi samo ta objekt, kajti poželjivost uboga imaginacijo enako kakor ta sposobnost presojanja. ${ }^{6}$

Tudi junak Celestine Kalist očitno ve, da človek zboli zaradi okvare sposobnosti predstavljanja (imaginacije), ki se začne v očeh, saj po Melibejini zavrnitvi neutolažljivo tarna: »Oh mis ojos, acordaos como fuistes causa y puerta por donde fue mi corazón llagado « (C, VI, 157). ${ }^{7}$ Tudi naslednja etapa njegove bolezni se ujema z Gordonijevim opisom. Melibeja je »bolnika « tako obsedla, da si - ker je ne more videti - v domišljiji pričara njeno podobo: »Pero tú, dulce imaginacion, tú que puedes, me acorre. Trae a mi fantasía la presencia angélica de aquella imagen luciente « ( $C$, XIV, 282). Ko začne hvaliti lepoto posameznih delov njenega telesa: »Comienzo por los cabellos...« ( $C, \mathrm{I}, 44$ in nasl.), se spomnimo na Andreja Kaplana, ki pravi, da ljubezen ne nastane iz kakršnegakoli dejanja, ampak samo iz misli, ki jih razum ustvari na podlagi videnih stvari. Ko duh izoblikuje ljubljeno postavo, si jo začne ljubimec želeti z vsem srcem in bolj ko misli nanjo, bolj se počuti prežarjen $\mathrm{z}$ ljubeznijo, dokler $\mathrm{v}$ celoti ne obnovi njenega bitja $\mathrm{v}$ domišljiji. Nato začne premišljevati o posameznih delih njenega telesa in si zamišlja njihove odzive, nazadnje pa si začne domišljati še skrite predele njene anatomije (De amore, 56-58).

Čeprav je veliko priročnikov predpisovalo domišljijsko doživljanje delov telesa ljubljenje osebe, njenega vonja in drugih lastnosti tudi kot pripravo na spolni odnos ali za zdravljenje impotence (Solommon, 1997, 53), Gor-

6 [L]a virtud estimatiua, que es la mas alta entre todas las virtudes sensibles, manda ala ymaginatiua e la ymaginatiua manda ala cobdiciable e la cobdiciable manda ala virtud ayrada e la virtud ayrada manda ala mouedora delos lacertos; e entonçes mueuen todo el cuerpo despernando la orden de la razon (Lilio, 521). Vsi navedki iz Gordonijevega Lilio de medicine (v nadaljevanju Lilio) so iz Dutton, B. in drugi (ur.), [Bernard de Gordon, Bernardus de Gordonio], Lilio de medicina, I, Madrid 1993.

7 Vsi poudarki v navedkih so moji. 
donij svari pred njim, ker lahko povzroči »passion" (v pomenu bolezen ali trpljenje): »[La causa] desta passion es corrompimiento, determinado por la forma e la figura que fuerte mente esta aprehensionada ...« (Lilio, 520). Tudi Francisco López de Villalobos govori o »corrupta imaginación por quien / algún hombre se aquexa de amores « (Sumario, 38) in nato našteje znamenja bolezni: raztresenost, nespečnost, neješčnost, šibkost, vzdihovanje, želja po samoti, jok, neenakomeren srčni utrip itd. ${ }^{8}$

Rojas je uporabil večino naštetega. Preden Kalist razglasi Melibejo za svojo boginjo, ukaže Semproniju, naj zapre okno in ga pusti samega z njegovo žalostjo, ki jo očitno tudi sam razume kot bolezen, saj v zvezi z njo omenja dva antična zdravnika:

Cierra la ventana y deja la tiniebla acompañar al triste, y al desdichado la ceguedad. Mis pensamientos tristes no son dignos de luz. ¡ Oh bienaventurada muerte aquella que deseada a los afligidos viene! ¡Oh si viniésedes agora, Crato y Galieno médicos, sentiríades mi mal! ${ }^{9}(\mathrm{I}, 29)$

Srednjeveško medicinsko avtoriteto Galena, ki je to bolezen v 2. stoletju prvi opisal, omenja v odstavku o simptomih tudi Bernard Gordonij, ko povzema primer, $v$ katerem naj bi slavni zdravnik diagnosticiral obravnavano motnjo:

8 De las señales que se muestran quando alguno está enamorado: Verasele al paciente perder sus continos / negocios y sueños, comer y bever, / congojas, suspiros y mill desatinos, / desear soledades y lloros mesquinos, / que no hay quien le valga ni pueda valer; / perdida la fuerça, perdido el color, / y quando le hablan d'amor luego llora, / y el pulso es sin orden y mucho menor, / y nunca s'esfuerça y se haze mayor / sino quando puede mirar su señora (Sumario, 40).

9 Poimenska omemba zdravnikov je polna jezikovnih, vsebinskih in zgodovinskih ugank. V različnih izdajah Celestine se poleg zapisa »Crato y Galieno« pojavljajo tudi različice "Eras y Crato«, »Creato e Galieno«, kar je pripeljalo pozneje do »Hipócrates e Galeno« in končno »Erasistrato y Galieno« oz. samo »Erasistrato«. Čeprav je mogoče najti v zgodovini medicine tudi imeni zdravnikov Herasa in Kratosa, je danes vseeno najširše sprejeta domneva, da gre za grškega zdravnika Erazistrata. Toda tudi ta temelji zgolj na domnevi: če je namreč v prvem stavku omenjeni zdravnik Erazistrat, bi bilo treba zvezo "piedad celestial « v naslednjem stavku brati kot "piedad de Seleuco", torej Selevkovo usmiljenje, s katerim je v antični zgodbi o kralju Selevku pomembno povezan Erazistrat. 
E por aquesta manera conoscio Galieno la passion de vn mancebo doliente, que estaua echado en vna cama muy triste e enmagreçido e el pulso era escondido e non ordenado e no lo queria dezir a Galieno; entonçes acontescio por fortuna que aquella muger que amaua passo delante del, e entonces el pulso muy fuerte mente e subita mente fue despertado; e commo la muger ouo passado, luego el pulso fue tornado a su natura primera; e entonçes conoscio Galieno que estaua enamorado; e dixo al enfermo: »tu estas en tal passion [= enfermedad] que a tal muger amas $[\ldots] \ll$... Lilio, 523)

Toda Sempronij si ne upa pustiti Kalista brez nadzora v takšnem stanju. Iz njegovega odgovora izvemo še druge bolezenske znake:

¿Cómo iré, que en viéndote solo dices desvaríos de hombre sin seso, sospirando, gemiendo, mal trovando, holgando con lo escuro, deseando soledad, buscando nuevos modos de pensativo tormento? (II, 86)

Bolezen ljubezen je imela tudi svoje ime, hereos, vendar je zanimivo, da Rojas v Celestini izraza ni neposredno uporabil, čeprav dosledno sledi vsem znakom bolezni in njenega zdravljenja. Iz besedil srednjeveških avtorjev (tudi zgoraj navedenih Villalobosa in Gordonija) je razvidno, da izraz hereos izvira iz stare Grčije. Takrat so zasnovali tudi razlage pojava, ki so nato preživele $\mathrm{v}$ arabskih in poznosrednjeveških medicinskih teorijah. Izhajajo iz epikurejskega materialističnega oziroma atomističnega prepričanja, po katerem se od vsakega objekta nenehno odleplja niz telesc, podob ali simulacra, njegovih reprodukcij; ta se po zraku z največjo hitrostjo vzvratno širijo na vse strani in vdirajo v oči gledajočega. Ko telesca zadenejo atome duše, človek občuti objekt (Lindberg, 1976, 2-3). Če ostanejo v telesu tistega, ki jih prejme, kot odzven še potem, ko ljubljena oseba odide, ga lahko sčasoma obvladajo in obnorijo ali povzročijo njegovo smrt. Poimenovanje hereos zato domnevno izvira iz grškega pojma eros, ujeti nekoga, oziroma tisti, ki lovi (Boase, 1977, 132). Prvo medicinsko besedilo, ki je v Evropo vneslo idejo, da je ljubezen bolezen - poglavje iz vademekuma Viaticum je Konstantin Afričan (1015-1087) prevedel iz arabščine $\mathrm{v}$ »De amore qui est eros dicitur« (Carrillo, 2000). 


\section{Bolezen visokega stanu: hereos - heroes}

Zapletenost vprašanj, povezanih z boleznijo ljubeznijo in izrazom zanjo, ima še širše - jezikovne, družbene in literarne - implikacije. Za vse tri vidike je ključno, da so žrtve te bolezni izključno moški visokega stanu. ${ }^{10}$

Gordonij takole razloži njeno ime: »E dize se hereos porque los ricos e los nobles, por los muchos plazeres que han, acostumbran de caer o incurrir enesta passion « (Lilio, 521). Arnald iz Vilanove pravi, da se bolezen (on zapiše heroes, ne hereos) imenuje tudi dominalis, gosposka; ne samo, ker napada gospode, ampak tudi, ker vedenje bolnikov spominja na pokoravanje služabnikov gospodarjem, tako da jih v vsem ubogajo. Ženska zasužnji dušo in telo moškega - prej gospodarja - tako neomajno, da jo zdaj priznava za svojo gospodarico (Solomon, 1997, 130). Villalobos pa je pojav povezal neposredno s trubadurji: »Amor hereos según nuestros autores / es una corrupta imaginación / por quien algún hombre se aquexa de amores; / y en este ques hito de los trouadores, / sin ser lisongero diré mi razón “ (Sumario, 38; prim. Boase, 1997, 132 in Carrillo, 2000).

Zaradi povezave med boleznijo in družbenim statusom so raziskovalci španske književnosti 15. stoletja - Boase (1977, 1978), Whinnom (1980), Wack (1990), Castells (1993), Solomon (1997), Carrillo (2000) in drugi usmerili pozornost na pomen medicinskih izsledkov za razvoj kulturne podobe amor hereos $\mathrm{v}$ dvorski literaturi. Moška domišljija, ki sproži bolezen, namreč poveličuje žensko podobno kakor sodobna dvorska lirika, ki jo časti kot idealizirani objekt. To ga v družbenem pogledu poniža: postane uslužen in podrejen in s tem prestopi norme svojega spola in moči. Wackova (1990) sugerira, da je možna tudi kronološka in terminološka povezava. Konstantinov Viaticum se je namreč razširil in postal priljubljen ravno v času, ko so se v literaturi pojavile konvencije o idealizirani dvorski ljubezni. Dejstvo je tudi, da so o bolezni največ pisali zdravniki iz Montpellierja prav

10 Wackova $(1990,109-125)$ piše, da je bolezen v toledskih prevodih Avicenne in drugih arabskih piscev maskuliniziral Gerard iz Kremone. Zakaj je to storil in koliko ima to opraviti z novim pojmovanjem ženske, ki se je razvijalo v tistem času, ni jasno. Je pa večina piscev v srednjem veku to sprejela kot dejstvo. Vigier (1979) pa med tistim, ki so vendarle trdili, da bolezen prizadene oba spola, ali pa to možnost vsaj dopuščali, navaja Janeza iz Gaddesdena (1280?-1361), ki je v Rosa medicinae zapisal: »De genere melancoliae est amor hereos in istis mulieribus et viris qui inordinate diligunt.« 
$\mathrm{v}$ času, ko je na bližnjih provansalskih dvorih cvetela trubadurska lirika in ko je Kaplan napisal svoj De amore. Če sta se medicinski in dvorski diskurz dejansko srečala in medsebojno prepajala, bi to pomenilo, kakor pravi Carrillova (2000), da besede, ki v poeziji govorijo o šibkosti in norosti, niso zgolj metafore, temveč reference na dobro poznane medicinske teorije.

A čeprav tako znanstvena kot literarna besedila ustvarjajo podobo, da je bolezen obsedala ves predstavni svet, so v razpravah nanizani zgolj »teoretični« zapisi o bolezni, njenih vzrokih in posledicah, o kakšnem konkretnem primeru amor hereos pa ni zdravniških poročil. Zato se upravičeno postavlja domneva, da bolezen sploh ni segala ne na področje družbene prakse ne ideologije in je bila torej le skupek znanstvenih in literarnih konvencij.

Zanimivo je, da je sočasno $\mathrm{z}$ estetiziranjem in splošnim uveljavljanjem pojmov, ki danes označujejo plemenito, dvorsko ljubezen, tudi na jezikovni ravni potekalo "poplemenitenje«, in sicer iz amor hereos v amor heroes. Tako je Arnald iz Vilanove svojo razpravo naslovil Tractatus de amore heroico in uporabil besede heroicus, heroys ali amor heroyeus. Po medicinski terminologiji so se ravnali tudi sholastični teologi in bolezen imenovali amor heroicus. Kako je prišlo do tega preobrata, ni povsem pojasnjeno. Carrillo (2000) povzema, da so se različice (amor eros, amor heros, amor hereos, amor heroes) oblikovale pri prevajanju iz arabščine v grščino, iz grščine $\mathrm{v}$ latinščino in iz arabščine v latinščino. Najverjetneje se je v grško besedo eros najprej zlil arabski pojem al-'ishq (tako je Avicenna v Kanonu naslovil razdelek o ljubezni in pomeni 'duševno motnja, ki se tako okrepi, da postane goreča in ekscesna ljubezen'), potem je prišlo do zmešnjave pri kontaminaciji z latinskim herus (gospod, gospodar), verjetno tudi s heros in herous (heroj in herojski), pri čemer je izvirni eros padel v pozabo. Tako naj bi zmotna etimologija spremenila arabsko »ljubezen-strast « v evropsko »herojsko ljubezen« (prim. Castells, 1993).

Zaplet v Celestini je dober primer takšnega srednjeveškega sinkretizma družbenih, "naravoslovnih « in literarnih elementov: oboleli Kalist je pripadnik brezdelnega plemiškega rodu (»de noble linaje«), ljubezen ga »napade« preko pogleda na Melibejo in dialogi med zaljubljencema potekajo tako, kot je to predpisovala dvorska poezija, oziroma to maniro smešijo. 


\section{Prognoza in oblike zdravljenja}

Edina rešitev za bolnika je, da ljubljena oseba sprejeme njegovo ljubezen in se tudi v njej naseli njegova podoba. Če pa ga zavrne, se razvijejo vsi psihosomatski znaki, ki peljejo v norost in smrt: »La pronosticacion es tal que sy los hereos non son curados caen en mania o se mueren, " poudarja Gordonij (Lilio, 523). Tudi v drugih razpravah o ljubezni je opisu vzrokov in simptomov bolezni najprej sledila alarmantna prognoza, največ prostora pa je bilo namenjeno postopkom za njeno lajšanje ali preprečevanje: od povsem praktičnih rešitev do moralističnih prijemov v smislu obsojanja ljubezni.

Kalistov služabnik presenetljivo dobro pozna to izročilo. Ko ga tožeči Kalisto pokliče k sebi, prevzame vlogo »zdravnika«. Zaveda se, da je prvi pogoj za uspešno zdravljenje diagnosticiranje bolezni: »[E]l comienzo de la salud es concocer hombre la dolencia del enfermo « $(C, \mathrm{I}, 35)$. V repliki vstran ( $C, \mathrm{I}, 31-32)$ premišlja, kaj naj stori z bolnikom. Če ga pusti samega, kakor si ta želi, se utegne sam pokončati. Nesmiselno pa je tudi ostati pri njem, saj zavrača družbo. Stara modrost priporoča, naj ga pusti, da se »omedi«, in bo potem dovzetnejši za pomoč. Vendar Sempronij vseeno ne tvega, zavedajoč se, da bi mu gospodarjeva smrt povzročila hude preglavice. Zato se odloči, da ostane pri njem, saj je za prizadetega bolje, če toži v družbi: »Por otra parte, dicen los sabios que es grande descanso a los afligidos tener con quien puedan sus cuitas llorar, y que la llaga interior más empece« $(C, \mathrm{I}, 31-32)$. Ve torej, da je treba bolnika najprej zdraviti z blažjimi sredstvi. Na Kalistovo željo mu poda lutnjo, a je razglašena, podobno kot gospodar, čigar hotenje ne uboga več razuma. Ko Kalist zahteva, naj mu zapoje najbolj žalostno pesem, Sempronij lahko samo še ugotovi, da je ubogi mož nor. Obljubi mu, da ga bo pozdravil: »Yo te sanaré« $(C, \mathrm{I}, 34)$. In tako se odloči, da mu bo z razvedrili krajšal čas, da ne bo mislil na bolečino, ki mu jo je prizadejala kruta gospodična.

»Učeni« služabnik očitno obvlada eno od mnogih metod zdravljenja, ki so jih predpisovali tedanji priročniki - da je treba trpečega zamotiti s prijetnimi rečmi. Strokovnjaki so za začetek svetovali skromno dieto z ne preveč hrane, predvsem pa brez začimb, mesa, ptičev, ostrig, torej dražilnih jedi. Zaljubljenec je moral nositi lahko obleko in se čim več gibati na svežem zraku, treba ga je bilo razvedriti z zabavami, športom, kot sta lov 
in zmerno jahanje, in s potovanji v prijetne kraje. Nekateri so predpisovali tudi kopeli, spanje in rahlo (nekateri tudi močno) opitost, odsvetovali pa ples in poslušanje neustreznih pesmi (Vigier, 1979; Wack, 1990; Carrillo, 2000). Toda takšni postopki so dosegli želeni učinek le pri blažjih oblikah ali začetnih stanjih bolezni. Pri akutnejših primerih je bilo treba terapijo ustrezno stopnjevati. Za bolnike, ki si niso dali dopovedati zlepa, so nekateri predlagali drastične ukrepe, Gordonij na primer bičanje: »E sy ala razon no es obediente e es mancebo, sea castigado en tal manera que sea açotado fuerte mente e muchas vezes, fasta que comiençe a feder « (Lilio, 524).

Ker se je bolezen najavila $\mathrm{z}$ motnjami v imaginaciji in je šele potem začela spodjedati telo, se je namesto uporabiti telesne terapije zdelo smiselnejše usmeriti vsa prizadevanja v ozdravitev predstavnih funkcij: podobe, ki so sprožile proces obolevanja, je treba odstraniti ali zamenjati z njihovim nasprotjem. Pri tem je imela ključno vlogo beseda. Srednjeveški medicinski teoretiki so si bili enotni v tem, da na zaviranje amor hereos bolj kot katerekoli druge besede vplivajo tiste, ki se nanašajo neposredno na ljubljeni objekt. Gordonij, na primer, je v priporočilih, kako zaljubljenca odvrniti od povzročiteljice njegovih težav, posebno slikovit in krut. Svetuje, naj pripeljejo kakšno grdo starko, da mu bo s podrobnim navajanjem skrajno odbijajočih lastnosti (garjavosti, pijanosti, umazanosti, božjastnosti smrdljivosti, mesečne čišče) očrnila in priskutila žensko, v katero se je »zagledal«:

$[P]$ or ende, busque se vna vieja de muy feo acatamiento, con grandes dientes e baruas e con fea e vil vestidura, e traya de baxo de si un paño vntado conel menstruo de la muger; e venga al enamorado e comiençe a dezir mal de su enamorada, diziendo le que es tiñosa e borracha, e que se mea enla cama, e que es epilentica e fiere de pie e de mano e que es corrompida [...] e que le fiede el fuelgo e es suzia; e diga otras muchas fealdades, las quales saben las viejas dezir e son para ello mostradas [...] (Lilio, 525-256; prim. Márquez Villanueva, 1993, 30-34)

Čeprav se vsi razpravljalci morda niso strinjali z njim, je s podobnimi nasveti, kako prestrašiti bolnika glede posledic njegove bolezni (bodisi na tem ali onem svetu) ali karseda očrniti vir njegovih tegob, mogoče pojasniti Sempronijev znameniti ženskam sovražni monolog iz prvega dejanja. Prav takšni »verbalni mojstri« - konfabulatorji, so namreč s svojim pretirava- 
njem pri nizanju pokvarjenosti ženskega značaja in telesa, razvili srednjeveško mizoginijo do vrhunca. Zgledovali so se lahko po antiki, predvsem po Lukreciju in Ovidijevih Zdravilih za ljubezen. ${ }^{11} \mathrm{~V}$ španskih književnih delih poznega srednjega veka je kar nekaj konfabulatorjev: v Corbachu je ta lik kar avtor sam, nadduhovnik alfonso Martínez de Toledo, v Roigovi knjigi Spill ima vlogo konfabulatorja Salomon, ki nagovarja samega avtorja, najbolj znan literarni lik pa je Tefeo, ki ga Diego de San Pedro uvede na koncu Cárcel de amor.

Kalist se vztrajno upira Semprinijevemu izvajanju, podobno kot pri drugih literarnih zaljubljenicih je torej konfabulatorksa metoda zdravljenja pri njem neuspešna. Ko služabnik poskuša še z zadnjim argumentom o ženski manjvrednosti: »Ansí como la materia apetece a la forma, ansí la muger al varón, « gospodar razume namig po svoje: »¡Oh triste!, y ¿cuándo veré yo eso entre mí e Melibea?« $(C, \mathrm{I}, 46)$. Kalistov nepoučen (morda sprenevedav) odgovor nakaže, da mu konfabulatorjevi terapevtski posegi niso pogodu in da potrebuje nekaj drugega. Antično misel o obliki in snovi, s katero želi Sempronij poznavalsko podkrepiti žensko manjvrednost oziroma nepopolnost, si v pohotni norosti razlaga po svoje: da ženska stremi po združitvi z moškim zaradi spolnih vzgibov. ${ }^{12}$ Služabnik dojame njegovo nestrpnost in sklene, da mu bo pomagal: »Y porque no te desesperes, yo quiero tomar esta empresa de complir tu deseo." Kalist mu navdušeno obljubi nagrado in Sempronij vstran doda, da mu bo v tem primeru Melibejo pripeljal naravnost v posteljo: »Con todo, si destos aguijones me da, traérgela he hasta la cama« $(C, \mathrm{I}, 46-47)$.

Zadnja terapevtska stopnja zdravljenja, telesna združitev, izvira iz prepričanja, da je treba zaradi psihosomatskega vzroka bolezni poskrbeti tako za telo kot za dušo. Večina zdravnikov je sodila, da ima koitus blagodejne učinke in so ga predpisovali tudi s terapevtskim namenom. Avicenna poudari, da ljubezen sama po sebi ni bolezen, lahko pa to postane, kadar ni izpolnjena. Če spolno poželenje ni uresničeno, spomin apetitnim funkcijam nenehno priklicuje užitek in še povečuje željo, kar pripelje do zapletov.

11 Prim. Ovidij, v. 325-342: »Kolikor moreš grdó dekletove čare očrni ...«

12 Fothergill-Payne (1993) uporabi ta primer (zmotne) razlage Aristotelove sentence za prikaz, kako se metaforični pomen v sentenci »spusti« na dobesedno raven. 
Zdravnikom svetuje, naj bolnika, če ne zaleže drugo zdravljenje, združijo z žensko. Avicennovo tezo o spolnem odnosu kot najučinkovitejšem zdravilu so sprejeli vsi pomembnejši zdravniki: Konstantin Afričan, Gerard iz Kremone, Arnald iz Vilanove, Bernard Gordonij, Villalobos, Marsilio Ficino itn. Vključena je bila tudi v Konstantinov Viaticum (Ferrand, 1990, 59-72). Rojasov sodobnik Alfonso de Madrigal, El Tostado, ki je bolezen hereos opisal po Gordonijevem zgledu, je v El libro de las diez questiones vulgares takole opisal škodljive posledice nepotešitve:

Si no obedescamos al su movimiento [de Cupido] executando los carnales ayuntamientos, sigue crescimiento de ardor que consume las humedades tiernas, y el cuydado cerca de esto afflige e deseca y enmagresce, y síguense algunas vezes graves enfermedades, en especial si cae el amador en la passión llamada por los médicos amor hereos, ca trahe ésta alos hombres a punto de se perder. (nav. po Boase, 1977, $132-133)^{13}$

\section{Vloga zvodnice}

Treba je poudariti, kakor opozarja Vigier (1979), da so ljubimcu priporočali spolno združitev z žensko, v katero je bil zaljubljen, le v skrajnem primeru. Bilo je veliko bolj priporočljivo, da se teši z drugimi ženskami. Pri tem so sledili Ovidiju, ki je priporočal, naj se zaljubljeni moški oddalji od ljubljene ali se preda ljubezni do več žensk: »Ljubici hkrati imejte po dve, tudi to priporočam: / večji junak pa je, kdor zmore imeti jih več« (Remedia, 441-442). Bernard Gordonij to svetuje že v začetni fazi, med blažjimi načini: »[e] despues faz le que ame a muchas mugeres, porque oluide el amor dela vna «, in tudi on se sklicuje na Ovidija: »como dize Ouidio: 'fermosa cosa es tener dos amigas, pero mas suerte es si pudiere tener muchas' « (Lilio, 534). Villalobos pa omeni tudi osebo, ki lahko posreduje pri tem dejanju - zvodnico: »Noveno, alcahuetes le hagan querer / a otras señoras por mas distra-

13 Prepričanje, da je - ko odpovejo vsa medicinska sredstva - zaljubljenčevo zdravje odvisno samo še od izvoljenke, veje tudi iz dvorskih pesmi. Elena Carrillo (2000) kot primer navaja verze Álvara de Villasandina iz Cancionera de Baena, ki je izgubil zaupanje v zdravniško pomoč in spoznal, da ga lahko reši smrti le njegova dama: "Señora, cero / que d'aquesta enfermedad / tarde o nunca sanaré. / Médico nin çirugiano / non han tanta abtoridad / que me pudiesen dar sano.« 
ello« (Sumario, 41). Zdravniki so pripisovali zvodnicam pomembno vlogo; zaljubljenega namreč zamotijo $\mathrm{z}$ drugimi ženskami, lahko mu pomagajo do poroke, mu priskrbijo izkušeno starejšo žensko, da ga uvedejo v skrivnosti ljubezni, mu pripravijo ljubezenske napoje, ga opijejo itn.

Poznavanje teh okoliščin je nujno za razumevanje Celestine. Na izvajanju metod zdravljenja namreč temelji vsa zgodba, ki jo zaplete in razplete naslovna junakinja. Moč njenega lika je tako velika, da je preglasila vse druge značaje, tudi oba ljubimca, po katerih se je delo sprva imenovalo. Njeno ime je po antonomaziji postalo $\mathrm{v}$ španščini eden od sinonimov za njen poklic. Sempronij Kalistu prvič omeni Celestino z besedami: „Días ha grandes que conosco en fin desta vezindad una vieja barbuda, que se dice Celestina, hechicera, astuta, sagaz en cuantas maldades hay « $(C, \mathrm{I}, 47)$. Opis ustreza že omenjenemu Gordonijevemu nasvetu: »Busque se vna vieja de muy feo acatamiento, con grandes dientes e baruas e con fea e vil vestidura $($ Lilio, 525-256).

A Rojasova »alcahueta" in »vieja falsa» ima drugačno nalogo tako od Gordonijeve starke kot od Villalobosove zvodnice. Celestina namreč ne črni Melibeje, da bi obsedenega Kalista odvrnila od nje, pa tudi drugih žensk mu ne priskrbi, da bi preusmerila njegovo pozornost od nje. Zvodničin poklic v tej zgodbi ni zdraviti bolezni ljubezni, ona $\mathrm{v}$ resnici od nje živi. Zato podpihuje Kalistovo zagledanost in svojo strategijo preusmeri še na Melibejo. Najprej ji pove, da je nekdo zbolel, in jo prosi za na njeno pomoč: "Yo dejo un enfermo a la muerte, que con sola una palabra de tu noble boca salida que le lleve metida en mi seno, tiene por fe que sanará, según la mucha devoción tiene en tu gentileza « $(C, \mathrm{IV}, 124)$ in zaigra na usmiljenost do trpečih. Mladenka se takoj odzove, saj je vzgojena po krščanskih vrednotah:

Por una parte me alteras y provocas a enojo; por otra me mueves a compasión; [...] Que yo soy dichosa, si de mi palabra hay necesidad para salud de algún cristiano. Porque hacer beneficio es semejar a Dios [...] en alguna manera es aliviado mi corazón, viendo que es obra pía y santa sanar los apasionados y enfermos. (C, IV, 124-132) 
Besedi »apasionados y enfermos«, prvo je v svoji tožbi uporabil tudi Kalist, sta dvoumni, kar ponovno dokazuje, da je dvogovor med Celestino in Melibejo prepreden s podteksti in sprenevedanji. Poteka namreč po predpostavkah: vem, da veš, da vem, o čem govoriš. Melibeja je pripravljena zdraviti hudo bolne, a uporaba besede »apasionados« (trpeči v medicinskem pomenu in razvneti od strasti) daje slutiti, da se zaveda, za kakšno bolezen gre, in tudi, kako jo je treba zdraviti, ter da si to tudi želi. In dejansko je Celestina hitro dosegla svoje - združila ljubimca - in s tem potrdila Sempronijeve besede: »A las duras peñas promoverá e provocará a lujuria, si quiere $(C, \mathrm{I}, 47) .{ }^{14}$

\section{Smrtni izid}

Prav »lujuria«, sla, je odločila o tragičnem razpletu zgodbe. Zaradi Celestininih posegov umreta glavna junaka: Kalist se ponesreči, Melibeja pa sledi vzornim ženskam iz zgodovine - njena smrt je posledica ljubimčeve smrti. Če nadaljujemo interpretacijo z vidika amor hereos, je kazen, ki je ugonobila Kalista, eksemplarična, ker je za ozdravljenje svojega poželenja najel Celestino, namesto da bi upošteval nasvete profesionalcev. Bernarda Gordonija, denimo, ki je opozoril na nevarnost pri pretiravanju s terapijo (izsušitev) in jasno opredelil, komu ne koristi (zaljubljenim), pri tem pa dodal še, komu je namenjena (tistim, ki imajo zanjo »dovoljenje«):

Deuedes de entender que el coytu demasiado deseca, e el tal no conuiene alos hereos o enamorados ni alos tristes ni alos melancolicos; pero alos que es permisso el coytu bien conuiene, sy templada mente se fiziere, segund Auicena. E segund el

14 Tako velikega uspeha pa si ni zagotovila le s spretnim jezikom, ampak zelo verjetno tudi s čarovniškimi sposobnostmi. O tem, kako Celestina »zaljubi« Melibejo s čarovniškimi prijemi, gl. Ferrand (1990, 83-97) in Solomon (1997). Za izčrpno argumentacijo interpretacije, po kateri naj bi bila Melibeja žrtev Celestininega uroka (philocaptio), in ne zgolj njenih prepričevalskih sposobnosti, pri čemer od IV. dejanja naprej ni več odgovorna za svoja dejanja, gl. Russell (1978, pogl. »La magia, tema integral de La Celestina «, 143-276). Cátedra García (1989, 4. pogl. »Amor y magia «, 85-112) povzema polemiko v zvezi z vlogo magije v Celestini: nekateri menijo, da je ta ena od vsebinskih osi Celestine, drugi, da gre za povsem obrobno vprašanje (npr. Fothergill-Payne, 1988), nekateri pa zagovarjajo njeno dvojno, vzporedno vlogo v dogajanju. 
templamiento es fecho segund Galieno, que se faga por tantos interualos que el cuerpo se sienta aleuiado, e que coma mejor e duerma mejor. Pues aquel coytu es templado que alegra e escalienta e faze buena digestion. Bien conuiene alos que lo tienen permisso, quiere dezir alos que tienen licencia para lo fazer, en tal manera que lo fagan templada mente. (Lilio, 526)

Kalist je z Melibejo pretiraval, skoraj ves mesec je ponoči hodil k njej, kar je pred smrtjo priznala tudi Melibeja: »Del cual deleitoso yerro de amor gozamos cuasi un mes « $(C, \mathrm{XX}, 333)$. To bi mu odsvetoval vsak šolan zdravnik. Gordonij sicer razen »splošne izsušitve« ne navaja podrobno posledic, toda Solomon (1997, 55, 185, op. 20 in 21) omenja, na primer, Alberta Velikega, ki je zapisal tole prigodo: neki zaljubljeni menih je imel spolni odnos $\mathrm{z}$ lepo žensko sedemdesetkrat v eni noči in je zaradi tega umrl. Obdukcija je pokazala, da so se mu posušili možgani in skrčili na velikost granatnega jabolka, oči pa uničile. Albert sklepa, da pretirano izločanje semena predvsem izprazni možgane in sosednje organe, posledica pa je, da bolniku začne pešati vid, saj, kot piše že Aristotel, v glavi prav v področju oči nastaja največ semena. Zdravnik na dvoru Ivana II. Alfonso Chirino pa je svaril pred prepogostimi odnosi, ker da povzročajo vrtoglavico: »[L]a cabeça se anda aderedor [...] e esto conteçe de grant flema en el estómago o de vsar mucho de mugeres." (prim. Ranke-Heinemann, 1992, 184).

Kalistov konec je grozljiv poseg v telo, saj se to raztrešči v vsej veristični absurdnosti in ironiji. O okoliščinah smrti se bralec seznani iz besed drugih likov. Najprej služabnik Tristan naroči tovarišu, naj pobere gospodarjeve možgane, ki so se razleteli po tleh: »Coge, Sosia, esos sesos de esos cantos; júntalos con la cabeza del desdichado amo nuestro, « in nato poroča Melibeji: »Cayó mi señor Calisto del escala y es muerto. Su cabeza está en tres partes «15 (C, XIX, 324). Pozneje jih opiše še Melibeja očetu:

Y como esta pasada noche viniese según era acostumbrado, a la vuelta de su venida, como de la fortuna mudable estoviesse dispuesto e ordenado según su desordenada costumbre, como las paredes eran altas, la noche escura, la escala delgada, los

15 Verjetno zaradi treh lobanjskih vdolbin, kjer so po takratnem mnenju možgani. Prim. Agamben $(1998,113)$. 
sirvientes que traía no diestros en aquel género de servicio y él bajaba presuroso a ver un ruido que con sus criados sonaba en la calle, con el gran ímpetu que levaba, no vido bien los pasos, puso el pie en vacío y cayó, y de la triste caída sus más escondidos sesos quedaron repartidos por las piedras y paredes. (C, XX, 333)

Po Albertu Velikem bi bil vzrok Kalistove smrti torej tak: zaradi prepogostega druženja z Melibejo so se mu možgani začeli sušiti. Ko se je v naglici hotel spustiti po lestvi, ga je zajela vrtoglavica in ker mu je opešal vid, je spregledal klin ter padel s takšne višine, da so se mu posušeni možgani razleteli na vse strani. ${ }^{16}$

\section{BIBLIOGRAFIJA}

Archer, R., Misoginia y defensa de las mujeres: antología de textos medievales, Madrid 2001.

Agamben, G., Stanze: la parola e il fantasma nella cultura occidentale [1981], fr. prev. Stanze: parole et fantasme dans la culture occidentale, Pariz 1998.

Armas, F. A. de, La Celestina: An Example of Love Melancholy, Romanic Review, 66, 1975, 288-295.

Boase, R., The Origin and Meaning of Courtly Love: a Critical Study of European Scholarship, Manchester 1977.

Boase, R., The Troubadour Revival: a Study of Social Change and Traditionalism in Late Medieval Spain, London-Henley-Boston, Mass. 1978.

Capellanus, Andreas, De amore: tratado sobre el amor (ur. Creixell VidalQuadras, I.), Barcelona 1984.

16 Fothergill-Payne (1993) med mnogimi metaforami v Celestini, ki se dobesedno uresničijo in v bahtinovskem smislu prestavljajo duhovne vrednosti na konkretno telesno raven, posebej opozori prav na Kalistov padec: stanje duha, v katerem se je znašel zaljubljeni mladenič in ga označujejo metafore "robar el seso «, "salir de seso «, "sin seso«, »fuera de seso", "perder el seso«, se je končalo v dejanski izgubi tega telesnega organa. 
Castells, R., El mal de amores de Calisto y el diagnóstico de Eras y Crato, médicos, Hispania, 76, 1993, 55-60.

Cátedra García, P. M., Amor y pedagogía en la Edad Media, Salamanka 1989.

Demaitre, L., Doctor Bernard de Gordon: Professor and Practitioner, Toronto 1980 .

Ferrand, J., A Treatise on Lovesickness (ur. Beecher, D. A. in drugi), Syracuse, N. Y. 1990.

Fothergill-Payne, L., Celestina 'as a Funny Book': a Bakhtinian Reading, Celestinesca, 2, 17, 1993, 29-51.

Gascón Vera, E., La ambigüedad en el concepto del amor y de la mujer en la prosa castellana del siglo XV, Boletín de la Real Academia Española, 59, 1979, 119-155.

Gordonio, Bernardus de, Lilio de medicina, I (ur. Dutton, B. in drugi), Madrid 1993.

Jacquart, D. in drugi, Sexualité et savoir médical au Moyen Age, Pariz 1985.

Lacarra, M. E., La ira de Melibea a la luz de la filosofía moral y del discurso médico, Cinco siglos de Celestina: aportaciones interpretativas (ur. Beltrán, R. in drugi), Valencia, 1997, 107-120.

Lindberg, D. C., Theories of Vision from al-Kindi to Kepler, Chicago, Ill. 1976.

Lowes, J. L., The Loveres Maladye of Hereos, Modern Philology, 11, 191314, 491-546.

Lucena, L. de, Repetición de amores (ur. Ornstein, J.), Chapel Hill, N. C. 1954.

Márquez Villanueva, F., Orígenes y sociología del tema celestinesco, Barcelona 1993.

Martínez de Toledo, A., Arcipreste de Talavera o Corbacho (ur. González Muela, J.), Madrid $1985^{2}$.

Ovidius Naso, Publius, Remedia amoris. Zdravila za ljubezen, slov. prev. Barbara Šega Čeh, Ljubljana 2004. 
Ranke-Heinemann, U., Katoliška cerkev in spolnost, slov. prev. Tomo Virk, Ljubljana 1992.

Rojas, F. de, La Celestina: tragicomedia de Calisto y Melibea (ur. Rico, F.), Barcelona 2000.

Russell, P. E., Temas de La Celestina y otros estudios: del Cid al Quijote, México-Barcelona-Caracas 1978.

San Pedro, D. de, Obras completas, 2: Cárcel de amor (ur. Whinnom, K.), Madrid 1971.

Seniff, D. P., Bernardo Gordonio's Lilio de medicina: a Possible Source of Celestina?, Celestinesca, 1, 10, 1986, 13-18.

Solomon, M., The Literature of Misogyny in Medieval Spain: the Arcipreste de Talavera and the Spill, Cambridge 1997.

Vigier, F., Remèdes à l'amour en Espagne aux $\mathrm{XV}^{\mathrm{e}}$ et $\mathrm{XVI}^{\mathrm{e}}$ siècles, Travaux de l'Institut d'Études Hispaniques et Portugaises de l'Université de Tours, Tours 1979, 151-184.

Villalobos, F., El sumario de la medicina, v: Algunas obras del doctor Francisco López de Villalobos (ur. María Fabié, A.), Madrid 1886, 299-451.

Wack, M. F., Lovesickness in the Middle Ages: the Viaticum and its 11Ct. Commentaries, Philadelphia, Pa. 1990.

Whinnom, K., Construcción técnica y eufemismo en el Cancionero General, v: Historia y crítica de la literatura española (ur. Rico, F.), 1: Edad Media (ur. Deyermond, A.), Barcelona 1980, 346-349. 


\section{AMOR HEREOS: UNDERSTANDING LOVE AS SICKNESS IN FERNANDO DE ROJAS' LA CELESTINA}

Keywords: La Celestina, medieval literature, lovesickness, misogyny

\section{Abstract}

One of the most evident features of Fernando de Rojas' La Celestina is its omnipresent ambiguity. This does not involve merely literary convention or play, but has much broader implications: the conflicts between the opposing poles are so deep that they undermine the work's entire meaning. Because La Celestina is a clear example of medieval syncretism of social, "scientific," and literary elements, there are a large number of possible interpretations.

This article focuses on the possibility of explaining the story's tragic resolution from the viewpoint of medicine. It discusses one of the typically medieval aspects of La Celestina: the understanding of love as pathology (amor hereos), to which the hero is supposed to succumb and which is supposed to be the main cause of his death. The description of Calisto's illness, including the causes, symptoms, methods of treatment, and the consequences of unsuccessful treatment, relies upon medieval medical works, especially Lilium medicinae by Bernardo Gordoni and El Sumario de medicina by Rojas' contemporary Francisco López de Villalobos; these works combine medical knowledge from Classical Antiquity and Arabic tradition. Within the context of La Celestina, the role of the procuress, also mentioned in these medical manuals, is especially important; the power of this character in Rojas' novel is so great that it overpowers all other characters, including both lovers, after whom the novel was first named.

Surprisingly, the main features of amor hereos match the role and discourse of a lover in courtly literature: in both cases, the main characters come from the ranks of nobility; they fall in love at first sight, idealize the beloved woman, fall ill because of their unfulfilled (sexual) desire for the 
woman, and may even die. Although both scholarly and literary texts create the idea that this illness occupied the entire representational world, the discussions merely list "theoretical" records on the illness, its causes, and its consequences; however, there are no medical reports on any concrete cases of amor hereos. Therefore, the assumption legitimately arises that this illness was not part of social practice and ideology at all, and was thus merely a set of scholarly and literary conventions. 